\title{
THE SCIENCE OF DIFFERENCE THE INVISIBILITY OF WOMEN IN HEALTH SCIENCES
}

\author{
CARMe VALLS-Llobet
}

Women remained invisible in health sciences until the late twentieth century because they were not included in the cohorts used in researched studies. Thanks to the work done by different groups of feminist researchers, we were able to visualise the need to change those paradigms. But while gender perspectives have allowed us to research new aspects of science, gender has sometimes contributed to rendering female-specific health issues as invisible. For women to be treated equally, their differences have to be recognised, precisely so that the equal right of both sexes to quality of life can be defended. Therefore, the science of difference should be included in research and taught in all health science specialisations.

Keywords: gender and health, differential morbidity, gender perspective, equality, differences.

Women have organs they do not feel are their own, whose functions are alien to them, and which are used by experts in every field.

(Sau, 2000, p. 49)

\section{THE INVISIBILITY OF DIFFERENCE}

Medical science was born mainly in hospitals, where most pathologies are acute and are predominantly male. Women's complaints, discomfort and pain was not always visible, and the specific study of differences in pathologies between men and women did not start until the twentieth century. Women's health was studied and valued only as part of overall reproductive health, and this approach prevented exploration from a comprehensive perspective.

Lois Verbrugge (1985) was the pioneer in research into the differences in mortality between women and men. Her analyses started to prove that there were differences in the diseases that most commonly affected each group, highlighting the higher prevalence of chronic diseases and use of healthcare services among women. Her greatest contribution was proving that the perceived health status of women - poorer in comparison to men - was due to acquired risks and psychosocial aspects such as physical inactivity, unemployment, and physical and mental state, rather than being caused by innate biological differences.

These and other discoveries led medical science, which had postulated that studying male specimens was equivalent to studying human beings in general, to change its paradigms and start recognising that there were differences between women and men in the way they get sick, in symptom manifestation, pain causes, the prevalence of particular diagnoses, and the metabolisation of drugs, which act differently depending on biological sex or their interaction with the menstrual cycle. Until 1990, most research in all health science areas did not include women in their study cohorts. No work included women in its research, and so biological, clinical,

psychological, social, cultural, and environmental considerations regarding the differences between women and men were not taken into account.

Thus, research and education biases start with the absence of women from research cohorts. The living and working conditions of women and their 
psychosocial overload are not considered. For instance, women are considered in the abstract in the analysis of the evolution of pathologies, ignoring factors such as whether they have children, a family, if they are carers, or if they live in stressful conditions. We lacked, and are still deficient in, research into differential morbidity, disease evolution, and differential treatment effects. As we can see, gender biases in medicine are perpetuated in many ways, and gender stereotypes still remain, as detailed in Mujeres, salud y poder ("Women, health, and power", VallsLlobet, 2009).

\section{THE EFFORT OF FEMINIST RESEARCHERS}

Several feminist researchers from around the world paved the way for a change in health science research and education with a number of publications from the 1980s to the 1990s. Apart from Lois Verbrugge, we must also mention Sue V. Rosser, who published the first book on how to teach health science from a feminist perspective in 1986. She advocated for a change in study objectives and also in the individuals performing the research:

Health science would be formulated from a perspective other than that of the white, middle-and upper-class Western men [...]. Recognition of the importance of perspective leads directly to examining science and health from as many perspectives as possible: gender as a category of analysis, an interdisciplinary perspective, and differing race, class, and cultural perspectives.

(Rosser, 1986, p. 107)

This was one of feminism's first contributions to health science. Rosser valued and recognised the role that social class, ethnicity, and the differences between women and men - and among women, depending on their age and working conditions - could play in pathological processes or in the consumption of drugs. The object of study changed from abstract entities to specifying the context of those under study.

During the 1990s, an international movement of female researchers promoted the inclusion of women in clinical trials. The first step was taken by the North-American cardiologist Bernardine Healy, who, in 1993, while she was directing the United States National Institutes of Health (NIH), promoted the first law that required research projects to include women and take ethnicity differences into account in order to receive public funding (Freedman et al., 1995).

After these initial steps, albeit with equal measure of obstacles and strength, gender perspective was gradually incorporated into medical research and health care. In the journal JAMA (Journal of the American Medical Association), Vivian W. Pinn (2003) stated that women's health research had already passed the limits that constrained it to reproduction-related organs and hormones. It also concluded that health care must be based on biological sex differences, and that gender influences should be based on behavioural, geographical, cultural, economic, and social factors.

In the discussion about how to address science without hiding differences, while also integrating social conditions and biological differences, the biologist Evelyn Fox Keller deconstructed many of the stereotyped paradigms in health science, such as the role of egg and sperm cells in reproduction. For example, those who imaginatively described «brave sperm overcoming barriers and navigating through vaginas» did not consider the metabolic changes that occur in the egg at the same time which provide the necessary substrate for embryo formation. For Keller (2004), the impact of feminism on science should not be based on essences of femininity: «My aim was not to make science either more subjective or more

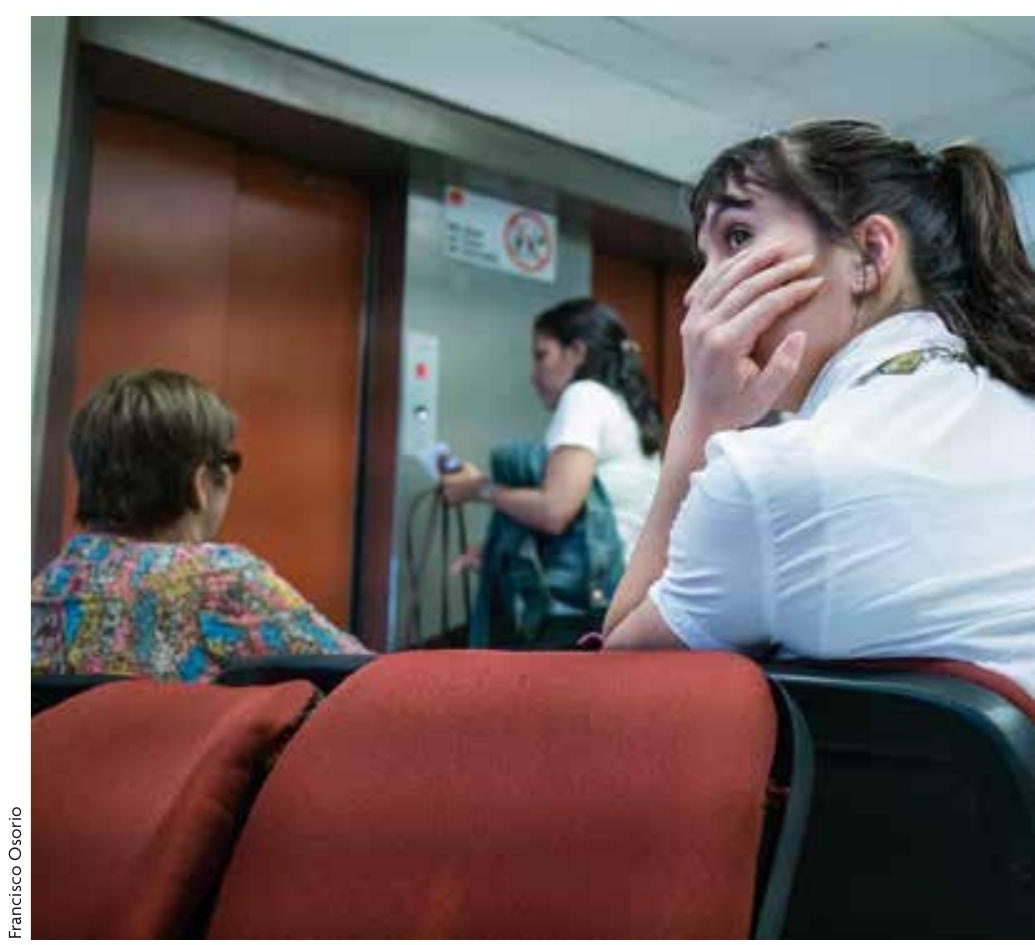

Medical science, which had postulated that studying male specimens was equivalent to studying human beings, had to change its paradigms and start recognising that there are differences between women and men in the way they get sick, in symptom manifestation, pain causes, the prevalence of particular diagnostics, and the metabolisation of drugs. 


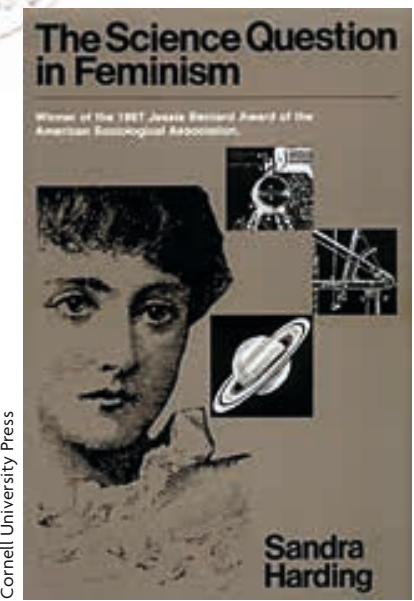

In The science question in feminism, Sandra Harding points out how the design and interpretation of inquiry has been developed again and again with a male gender bias. the work undertaken at Stanford University; under the management of Londa Schiebinger; they created a platform for studying sex and gender differences and innovating in this field: Gendered Innovations. ${ }^{1}$

Universities must all develop this task of differential sex and gender analysis, but, in basic biomedical research, we must also reflect upon the research conditions. For example, when performing cancer research using cell lines, are we taking into account any potential differences derived from their origin in a man or a woman? If we perform research using cells isolated in vitro, can we deduce if there will be any differences in behaviour inside

the body of a woman or a man, when interacting among themselves, with different sex hormones, or in stress conditions?

Karen Messing and Donna Mergler's research group, at the Center for Interdisciplinary Research on Well-Being, Health, Society, and Environment (CINBIOSE) in Canada, propose that we take time to reflect upon these issues at each research step, and state that every member of the team must develop sex and gender knowledge. Ultimately, the possible sex and gender implications of all research findings from any lab should always be discussed (Ritz et al., 2014).

In order to assess the quality of sex and gender additions to health research work, a team of researchers at the University of Zaragoza have developed a questionnaire containing almost twenty questions aimed at assessing gender perspectives throughout the entire research process (Tomás et al., 2014).

\section{HOW DO GENDER STEREOTYPES MANIFEST IN CLINICAL MEDICAL SCIENCE?}

Current clinical medicine biases the visibility of the most prevalent diagnostics in women in many ways: from ignoring menstruation-related disorders during adolescence to magnifying the consequences of the

${ }^{1}$ http://genderedinnovations.stanford.edu/ natural process of menopause, together with the appearance of chronic pathologies that produce pain and are more frequent among women (Valls-Llobet, 2006).

Underlying beliefs in the subconscious of many health professionals bias the clarity with which they address the diagnosis process and the treatment of many pathologies. Diagnostics are overshadowed by the assumption that risks and morbidity are equal in men and women, when in fact they are often different. Conversely, they consider biological or psychological differences where there are actually similarities. In the case of health care for women, complaints or symptoms are more frequently considered psychosomatic, so they are often prescribed anxiolytics and antidepressants at their first consultation. It is also frequent to minimise or maximise the pathology of a woman and the results of laboratory analyses without a scientific basis, exercise a reductionist paradigm of aetiologies, or mishandle the cause and effect relationship.

In addition, the fact that risks and toxicities are sometimes different for women and men, is often overlooked. For instance, the female body is a primary environmental chemical bioaccumulator (e.g., of pesticides, solvents, plastic derivatives, hydrocarbons from cars, etc.), because of their naturally higher body fat content.

\section{ADVANCEMENTS IN THE LAST FIFTEEN YEARS}

Since the end of the twentieth century, we have come to understand the incorporation of gender perspectives in education at many universities and in public policy as an advancement. The resolutions of the European Parliament regarding the situation of women's health in the European Community (collected in the Official Journal of the European Communities on 21 June 1999) are good examples. They are backed by the conclusions of the first International Congress on Women, Work, and Health, held in 1996 in Barcelona. The resolutions refer to the specificity of women's health problems and the existence of differences in general health between the sexes, and state that health care policy also requires differential treatment. Therefore, it recommends that member states should take these issues into account both in health analyses and in future actions.

Thus, the strategic plan of the National Institutes of Health in the United States (NIH Strategic Plan for Women's Health Research), within the Moving Into the Future with New Dimensions and Strategies: A Vision for 2020 for Women's Health Research

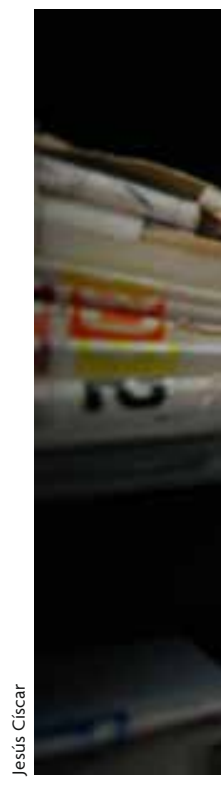




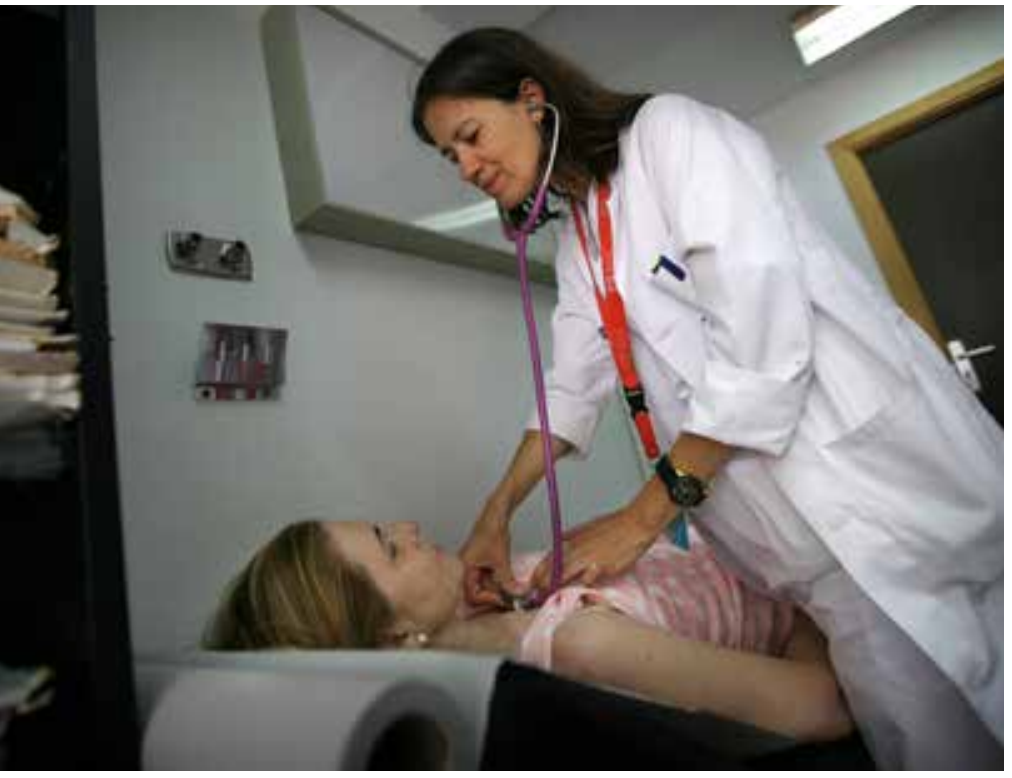

Current medicine still biases the visibility of the most prevalent diagnostics in women in many ways: from ignoring menstruationrelated disorders during adolescence to magnifying the consequences of the natural process of menopause, together with the appearance of chronic pathologies that produce pain and are more frequent among women.

framework from the NIH Office of Research on Women's Health $(\mathrm{ORWH})$, is great news for the future $^{2}$ (Tingen, Nangel, \& Clayton, 2013).

\section{SCIENCE OF THE DIFFERENCES}

Without the support of health care services empowering the science of difference, it is very difficult - for some women almost impossible - to change attitudes and values in a body that feels tired or exhausted after a double shift, because of the microviolence in life, at work, or in personal relationships, or due to nutritional deficiencies or endocrine and menstrual dysfunctions, in addition to those caused by the environment or by the excessive medicalisation of their body. In order to truly support them, medical science must take into account the differences in the way women get sick and the different risk factors in men and women. Thus, an increase in research and education about differential morbidity, stress, and mental and physical health is required.

${ }^{2}$ http://orwh.od.nih.gov/research/strategicplan/
The health care system needs to be progressively more sensitive to gender issues, creating specific spaces and protocols to make differential diagnosis easier. Therefore, the science of difference should be included in research and taught in all health science specialisations.

\section{REFERENCES}

Díaz, C. (2002). Conversational heuristic as a reflexive method for feminist research. International Review of Sociology, 12(2), 249-255. doi: $10.1080 / 0390670022000012477$

Fausto-Sterling, A. (2006). Cuerpos sexuados. Barcelona: Melusina. Freedman, L. S., Simon, R., Foulkes, M. A., Friedman, L., Geller, N.

L., Gordon, D. J., \& Mowery, R. (1995). Inclusion of women and minorities in clinical trials and the NIH Revitalization Act of 1993 - The perspective of NIH clinical trialists. Controlled Clinical Trials, 16(5), 277-285.

Harding, S. (1996). Ciencia y feminismo. Madrid: Morata. (Original work published in 1986).

Keller, E. F. (2004). What impact, if any, has feminism had on science? Journal of Bioscience, 29(1), 7-13. doi: 10.1007/BF02702556

Joel, D., Berman, Z., Tavor, I., Wexler, N., Gaber, O., Stein, Y., ... Assaf, Y. (2015). Sex beyond the genitalia: The human brain mosaic. Proceedings of the National Academy of Sciences, 112(50), 15468-15473. doi: 10.1073/ pnas.1509654112

Pinn, V. W. (2003). Sex and gender factors in medical studies: Implications for health and clinical practice. Journal of the American Medical Association, 289(4), 397-400. doi: 10.1001/jama.289.4.397

Ritz, S. A., Antle D. M., Côté, J., Deroy, K., Fraleigh, N., Messing, K., ... Mergler, D. (2014). First steps for integrating sex and gender considerations into basic experimental biomedical research. The FASEB Journal, 28(1), 4-13. doi: 10.1096/ fj.13-233395

Rosser, S. V. (1986). Teaching science and health from a feminist perspective. A practical guide. New York: Pergamon Press. Sau, V. (2000). Reflexiones feministas para principios de siglo. Madrid: Horas y HORAS.

Tingen, C., Nagel, J. D., \& Clayton, J. A. (2013). Monitoring the implementation of the National Institutes of Health Strategic Plan for Women's Health and Sex/Gender Differences Research: Strategies and successes. Global Advances in Health and Medicine, 2(5), 44-49. doi: 10.7453/ gahmj.2013.057

Tomás, C., Yago, T., Eguiluz, M., Samitier, M L., Oliveros, T., \& Palacios, G. (2014). A tool to assess sex-gender when selecting health research projects. Atención Primaria, 1-8. doi: 10.1016/j. aprim.2014.05.010

Verbrugge, L. M. (1985). Gender and health: An update on hypotheses and evidence. Journal of Health and Social Behavior, 26(3), 156-182. Valls-Llobet, C. (2006). Mujeres invisibles. Barcelona: Debolsillo. Valls-Llobet, C. (2009). Mujeres, salud y poder. Madrid: Editorial Cátedra.

Carme Valls-Llobet. Graduate in Medicine and Surgery in 1968. She is an internal medicine and endocrinology assistant, and the director of the Woman, Health, and Quality of Life Programme at the Centre for Health Care Analysis and Programmes (Centro de Análisis y Programas Sanitarios, CAPS) in Barcelona (Spain), where she focuses on research and education about health, women, and gender issues. She has promoted a network of female health professionals in Spain, the Red-Caps, and is the author of several papers and the books Mujeres y hombres: Salud y diferencias (Folio, 1994), Mujeres invisibles (Debolsillo 2006), and Mujeres, salud $y$ poder (Cátedra, 2009). 